\title{
Relationship Between Hospitalization Related Stress And Social Support Among Psychiatric Patients
}

\author{
Tahany S. Mohammed, Ikram I. Mohammed, Azza M. Abdel-Aziz \& Amany A. Mohammed. \\ Assistant Lecturer Psychiatric Nursing, Faculty of Nursing, Minia University, Egypt \\ Professor of Psychiatric Nursing, Faculty of Nursing, Assiut University, Egypt . \\ Assistant Professor of Psychiatric Nursing, Faculty of Nursing, Assiut University, Egypt .
}

\begin{abstract}
Hospitalization presents specific stress over those associated with illness. Privacy, independence and social support are reduced. Therefore, the aim of the study was to assess hospitalization related stress and social support among psychiatric patients and explore relationship between them. Patients and method: Sample included all patients admitted to the psychiatric inpatient units for six months from July to December 2013. Three tools were utilized to measure the variables of the study: Socio-demographic data sheet, Hospital Stress Rating Scale and Multidimensional Scale of Perceived Social Support Results revealed that, being hospitalized far away from home and being in the hospital during holidays were the major reasons for hospital related stress experienced by psychiatric patients.41.9 \% of psychiatric patients had moderate level of hospital stress and $22.9 \%$ of them had low level of social support. Conclusion: More than one third of the psychiatric patients had moderate level of hospital stress and nearly one quadrant of them had low level of social support. The results showed that there was no statistically significant relation between hospital stress and social support. Recommendations: Psycho educational programs are essential to educate psychiatric patients how to deal with hospitalization related stress and increase social support for them.
\end{abstract}

\section{Key words: Psychiatric Patients • Hospital Related Stress \& Social Support.}

\section{Introduction}

Hospitalization presents specific stress over those inflicted with illness. Privacy, independence and social support are reduced and there is uncertainty about what will happen in hospital. High rise buildings, lifts and long narrow corridors are unfamiliar to many. Patients are also likely to be faced with invasive and stressful medical procedures. The need for good communication and preparation from healthcare staff has already been emphasized (Dan-Set et al., 2007).

Psychiatric disorders are characterized by repeated hospitalizations. Individuals may be hospitalized for a day or several days, depending on how rapidly progress is made. Inpatient treatment is accompanied by many difficulties for the psychiatric patient and his/her family (Akpinar \& Buldukoglu, 2009). With admission to a psychiatric ward, several environmental stressors come into play. For example, the patient may have to be locked up for safety reasons and he or she will generally have little privacy. On a crowded psychiatric ward, the patient may be exposed to overstimulation (Krakowski \& Czobor, 1997). Furthermore, patients may be exposed to demanding therapies, resulting in frustration, anger or violence and may have to be secluded or may no longer be allowed to leave the ward. These measures may affirm distorted beliefs of the patient about being endangered on the ward, and may make him or her more afraid of the ward team (Nijman, 2002).

Social support is an element that can help individuals to reduce the amount of stress experienced as well as to help individual cope better in dealing with stressful situations (Dollete et al., 2004). Moreover, research has shown that social support plays an important role in managing psychological problems (Dollete et al., 2004). Lack of social support has been shown to be related to increased psychological problems such as depression, loneliness, and anxiety (Eskin, 2003), during stressful times, especially for people like elderly and victims of sudden uncontrollable life events (Sorkin et al., 2002).

In general population, social support buffers against subjects, stressful life events, increases adherence to medical treatment and increase recovery from medical illness (Di Matteo, 2004). Social support as a basic aspect of human life is often lacking in the lives of people with serious mental illness. Numerous studies have found people with mental illness, particularly those with schizophrenic disorders, to be socially isolated. Their networks are small compared with those of persons without mental illness and their relationships are often restricted to the immediate family, with few other social groups to refer to. The 
impact of social isolation ranges from poor outcomes in terms of quality of life and self- esteem to a less favorable illness course with more psychotic symptoms or more frequent and prolonged hospitalizations (Muller et al., 2007 \& Sawant \& Jethwani, 2010). Patients' social network size is strongly related to psychological symptoms, cognitive functioning, and also with quality of life and self-esteem (Goldberg et al., 2003).

It was concluded by Dirkzwager et al., (2003) that, social support is an important strategy which helps people to cope with traumatic experiences. Having effective social support has been shown to be one of the most significant correlates of well-being and has long been believed to positively impact health and guard against distress. Without enough support from family and friends, people would be in trouble and are vulnerable to depression, stress and anxiety. This finding was supported by Dollete et al., (2004) who found that social support could act as a protective factor that could decrease psychological problems such as stress. Likewise, Tao, et al., (2000) \& Calvete \& Smith (2006) suggested that support from family and friends have been found to reduce the impact of psychological problems.

\section{Significance of the Study}

Identifying hospitaization related stress among psychiatric patients, could be helpful in educating patients how to deal with such stress and providing social support for them. The nurse's ability to identify clues of psychosocial stress related to hospitalization better prepares her to develop a personalized plan for patient care. A nurse who is aware of such patient's stressors possesses the capability of decreasing the duration and scope of the stressful experience.

\section{Patients \& Method}

The Aim of The Study

was to assess hospitalization related stress and social support among psychiatric patients and explore the relationship between them.

\section{Research design}

A descriptive correlational design was used in the study; such design fits the nature of the problem under investigation.

\section{Setting of the study}

This study was conducted at the inpatient unit at Beni- Ahmed psychiatric hospital in Minia governorate. This hospital is affiliated to Ministry of Health. It consists of two floors; the first floor for the outpatient clinics, pharmacy and administrations. The second floor includes psychiatric inpatients and nursing offices. The hospital capacity is 50 beds for both sexes.

\section{Sample}

included all patients admitted to the psychiatric inpatient units for six months from July to December 2013. The number of patients who agreed to participate in the study was 70 (43 males and 27 females).

Tools of data collection:

- Socio-demographic and clinical

data sheet

This sheet was developed by the researcher to elicit data about patient's age, sex, educational level, marital status, occupation, and diagnosis.

\section{- Hospital Stress Rating}

\section{Scale (HSRS):}

This scale was developed by (Volicer \& Bohannon, 1975). It consists of 49 items designed to explore the perception of stressful events related to hospitalization. HSRS was modified by deleting 7 items, that don't fit to the current study. Every item has stress value; if the patient answered "yes" he got this value, if he answered "no" he got 0. Scoring system was calculated by aggregating the items of stress value, subtract the lowest value from the total, dividing the result on (3), and then adding this value to each ending interval to produce levels of hospital related stress. The scale was translated into Arabic language by the researcher and some modifications were done in the phrases to suit the study sample. The translated scale was checked for its content validity through a jury composed of 5 experts. The translated scale had shown a strong validity based on jury opinion. Reliability test was done to the modified scale using Cronbach's Alpha and proved to be reliable (0.84).

The total score of this scale ranges between 0 998.5. Those scoring 0 denoting (no stress), 13.9342.1 (mild stress), 342.2- 670.3 (moderate stress) and 670.4- 998.5 (severe stress).

- Multidimensional Scale of Perceived Social Support (MSPSS):

The MSPSS was developed by (Zimet et al., 1990). It is a 12-item self-report inventory to measure perceived adequacy of social support from family, friends, and significant others. Responses are scored on a 7-point scale ranging from (1-5). The scale was modified and translated into Arabic language by the researcher and checked for its content validity which was done by a jury of 5 experts.

Based on the opinion of jury, the scale responses categories were modified into a 5-point format, ranging from (strongly disagree) to (strongly agree). Scoring system is calculated by multiplying $(5 \times 12)$, subtract 60-12, dividing the result on (3), and then adding this value to each ending interval to produce levels of social support. Greater scores indicated higher levels of perceived social support. The 
translated questionnaire had shown adequate validity based on jury opinion. Reliability test was done to the modified scale using Cronbach's Alpha. The result revealed $\mathrm{r}=0.89$.

The total score is ranged from 5-60. Those scoring 12-28 dennoting (low acuity), 29-44 (moderate acuity) and 45-60 (high acuity) (Zimet, et al., 1990).

\section{Preparatory phase}

An official letter was sent from the dean of the Faculty of Nursing, Minia University, to the Director of Beni Ahmed psychiatric hospital in Minia to secure permission for data collection. The aim and process of study were briefly explained through direct personal communication with the patients, also oral or written informed consent was taken from patients' committee of the psychiatric patients' rights within the hospital.

\section{Pilot Study}

A pilot study was conducted at the beginning of the study. It included 15 patients during the $1^{\text {st }} 3$ weeks of data collection to investigate the feasibility of data collection tools and their clarity. The pilot study sample was included in the original sample because there were no modifications done for the study tools.

\section{Data collection}

Data were collected within 6 months from July to December 2013. Data collection was carried out 2 days per week from 10 am to $1 \mathrm{pm}$. patients were interviewed using the study tools after taking oral or written consent. The interview took about 30 minutes with every patient.

\section{Ethical considerations}

The following ethical considerations were considered throughout data collection:

- Permission to carry out the study was obtained from the Director of Beni Ahmed psychiatric hospital in Minia governorate.

- Oral or written informed consent was obtained from the patients and the participation in the research was elective.

- The researcher ensured that confidentiality was maintained during and after the research process.

- The participant's dignity and privacy were maintained and respected throughout the research process.

- Risk-benefits assessment: There was no risk during the application of the research.

\section{Statistical Analysis}

The content of each scale was analyzed, categorized and then coded by investigator. Patients' responses to each category were tabulated separately by using statistical package for social science (SPSS) version 16. Descriptive statistics were calculated as frequencies, percentage, mean and standard deviation. Chi square was also used. Probability (Pvalue) is considered significant at or less than 0.05 and considered highly significant at or less than 0.001 . 


\section{Results}

Table (1) Distribution of psychiatric patients according to their hospital stress rating scale items. $(n=70)$.

\begin{tabular}{|c|c|c|c|c|}
\hline \multirow{3}{*}{ Hospital stress rating scale items } & \multicolumn{4}{|c|}{ Frequency of responses } \\
\hline & \multicolumn{2}{|c|}{ Yes } & \multicolumn{2}{|c|}{ No } \\
\hline & No. & $\%$ & No. & $\%$ \\
\hline 1- Strangers sleep in the same room. & 25 & 36 & 45 & 64 \\
\hline 2- Eating at different times than usual. & 22 & 31 & 48 & 69 \\
\hline 3- Sleeping in a strange bed. & 21 & 30 & 49 & 70 \\
\hline 4- Wearing a hospital gown. & 19 & 27 & 51 & 73 \\
\hline 5- Having strange machines around. & 16 & 23 & 54 & 77 \\
\hline 6- Being awakened in the night by the nurse. & 14 & 20 & 56 & 80 \\
\hline 7- Having to be assisted with bathing. & 14 & 20 & 56 & 80 \\
\hline 8- Not getting newspapers, radio, or TV. & 30 & 43 & 40 & 57 \\
\hline 9- Having a roommate has too many visitors. & 17 & 24 & 53 & 76 \\
\hline 10- Having to stay in bed or the same room all day. & 45 & 64 & 25 & 36 \\
\hline 11- Being aware of unusual smells around you. & 26 & 37 & 44 & 63 \\
\hline 12- Having a roommate who is seriously ill. & 31 & 44 & 39 & 56 \\
\hline 13- Having a roommate who is unfriendly. & 29 & 41 & 41 & 59 \\
\hline 14- Not having friends visit you. & 32 & 46 & 38 & 54 \\
\hline $15-$ Being in a room that is too cold or too hot. & 13 & 19 & 57 & 81 \\
\hline 16-Thinking your appearance might be changed. & 26 & 37 & 44 & 63 \\
\hline 17- Being in the hospital during holidays. & 50 & 71 & 20 & 29 \\
\hline 18-Thinking you might have pain from procedures. & 39 & 56 & 31 & 44 \\
\hline 19- Worrying about your spouse being away from you. & 21 & 30 & 49 & 70 \\
\hline 20- Having to eat cold or tasteless food. & 20 & 29 & 50 & 71 \\
\hline 21- Not being able to call family on the phone. & 34 & 49 & 36 & 51 \\
\hline 22- Being cared for by unfamiliar doctor. & 24 & 34 & 46 & 66 \\
\hline 23- Being put in the hospital because of an accident. & 35 & 50 & 35 & 50 \\
\hline 24- Not knowing when to expect things. & 32 & 46 & 38 & 54 \\
\hline 25- Having the staff in too much of hurry. & 23 & 33 & 47 & 67 \\
\hline 26- Thinking about losing income because of illness. & 32 & 46 & 38 & 54 \\
\hline 27- Having medications cause you discomfort. & 29 & 41 & 41 & 59 \\
\hline 28- Having nurses or doctors talk too fast. & 23 & 33 & 47 & 67 \\
\hline 29- Feeling you are getting dependent on medications. & 18 & 26 & 52 & 74 \\
\hline 30- Not having family visit you. & 27 & 39 & 43 & 61 \\
\hline 31- Being hospitalized far away from home. & 55 & 79 & 15 & 21 \\
\hline 32- Having sudden hospitalization. & 40 & 57 & 30 & 43 \\
\hline 33- Not having your call light answered. & 25 & $\overline{36}$ & 45 & 64 \\
\hline 34- Not having enough insurance. & 25 & 36 & 45 & 64 \\
\hline 35- Not having your questions answered. & 23 & 33 & 47 & 67 \\
\hline 36- Missing your spouse. & 22 & 31 & 48 & 69 \\
\hline 37- Not getting relief from pain medications. & 11 & 16 & 59 & 84 \\
\hline 38- Not knowing the result or reasons for treatment. & 28 & 40 & 42 & 60 \\
\hline 39- Not getting pain medication when you need it. & 21 & 30 & 49 & 70 \\
\hline 40- Not knowing for sure what illness you have. & 24 & 34 & 46 & 66 \\
\hline 41- Not being told what your diagnosis is. & 29 & 41 & 41 & 59 \\
\hline 42- Knowing you have a serious illness. & 10 & 14 & 60 & 86 \\
\hline
\end{tabular}


Table (2): Distribution of psychiatric patients according to their perceived social support scale items (n=70).

\begin{tabular}{|c|c|c|c|c|c|c|c|c|c|c|}
\hline \multirow{3}{*}{ Social support scale items } & \multicolumn{10}{|c|}{ Frequency of responses } \\
\hline & \multicolumn{2}{|c|}{$\begin{array}{l}\text { Strongly } \\
\text { agree }\end{array}$} & \multicolumn{2}{|c|}{$\begin{array}{l}\text { Mildly } \\
\text { agree }\end{array}$} & \multicolumn{2}{|c|}{ Neutral } & \multicolumn{2}{|c|}{$\begin{array}{c}\text { Mildly } \\
\text { disagree }\end{array}$} & \multicolumn{2}{|c|}{$\begin{array}{l}\text { Strongly } \\
\text { disagree }\end{array}$} \\
\hline & No & $\%$ & No & $\%$ & No & $\%$ & No & $\%$ & No & $\%$ \\
\hline $\begin{array}{l}\text { There is a special person who is } \\
\text { around when I am in need. }\end{array}$ & 13 & 18.6 & 13 & 18.6 & 6 & 8.6 & 18 & 25.7 & 20 & 28.6 \\
\hline $\begin{array}{l}\text { There is a special person with } \\
\text { whom I can share my joys and } \\
\text { sorrows. }\end{array}$ & 13 & 18.6 & 11 & 15.7 & 8 & 11.4 & 18 & 25.7 & 20 & 28.6 \\
\hline My family really tries to help me. & 16 & 22.9 & 8 & 11.4 & 13 & 18.6 & 15 & 21.4 & 18 & 25.7 \\
\hline $\begin{array}{l}\text { I get the emotional help and } \\
\text { support I need from my family. }\end{array}$ & 22 & 31.3 & 9 & 12.9 & 9 & 12.9 & 16 & 22.9 & 14 & 20 \\
\hline $\begin{array}{l}\text { I have a special person who is a } \\
\text { real source of comfort. }\end{array}$ & 11 & 15.7 & 4 & 5.7 & 16 & 22.9 & 18 & 25.7 & 21 & 30 \\
\hline My friends really try to help me. & 15 & 21.4 & 22 & 31.4 & 9 & 12.9 & 14 & 20 & 10 & 14.3 \\
\hline $\begin{array}{l}\text { I can count on my friends when } \\
\text { things go wrong. }\end{array}$ & 21 & 30 & 20 & 28.6 & 7 & 10 & 11 & 15.7 & 11 & 15.7 \\
\hline $\begin{array}{l}\text { I can talk about my problems witk } \\
\text { my family. }\end{array}$ & 14 & 20 & 13 & 18.6 & 16 & 22.9 & 15 & 21.4 & 12 & 17.1 \\
\hline $\begin{array}{l}\text { I have friends with whom I can } \\
\text { share my joys and sorrows. }\end{array}$ & 17 & 24.2 & 16 & 22.9 & 13 & 18.6 & 14 & 20 & 10 & 14.3 \\
\hline $\begin{array}{l}\text { There is a special person in my life } \\
\text { who cares about my feelings. }\end{array}$ & 9 & 12.9 & 10 & 14.3 & 15 & 21.4 & 18 & 25.7 & 18 & 25.7 \\
\hline $\begin{array}{l}\text { My family is willing to help me } \\
\text { make decisions. }\end{array}$ & 15 & 21.4 & 8 & 11.4 & 18 & 25.7 & 20 & 28.6 & 9 & 12.9 \\
\hline $\begin{array}{l}\text { I can talk about my problems with } \\
\text { my friends. }\end{array}$ & 18 & 25.7 & 16 & 22.9 & 13 & 18.6 & 15 & 21.4 & 8 & 11.4 \\
\hline
\end{tabular}

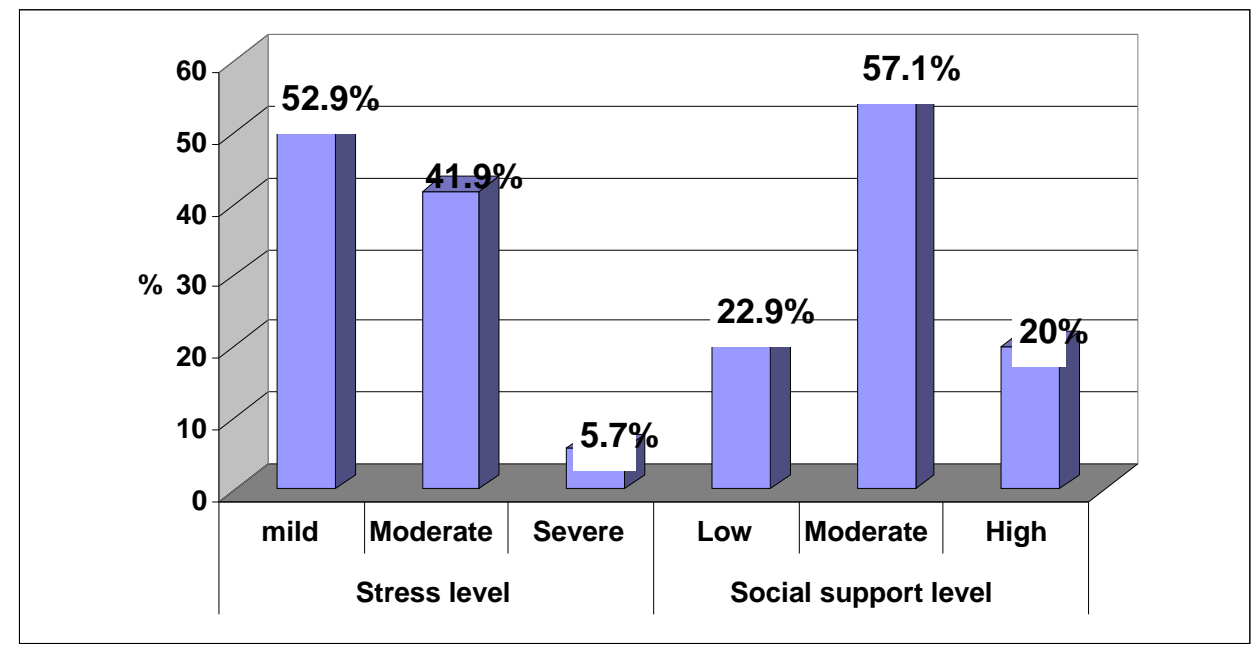

Figure (1): Distribution of levels of hospital stress and perceived social support among psychiatric patients $(n=70)$ 
Table (3): Relationship between hospitalization related stress levels and perceived social support levels $(n=70)$

\begin{tabular}{|c|c|c|c|c|c|c|c|c|c|}
\hline \multirow{3}{*}{$\begin{array}{c}\text { Hospitalization } \\
\text { related stress } \\
\text { levels }\end{array}$} & \multicolumn{9}{|c|}{$\begin{array}{c}\text { Perceived social support levels } \\
\end{array}$} \\
\hline & \multicolumn{2}{|l|}{ low } & \multicolumn{2}{|c|}{ Moderate } & \multicolumn{2}{|c|}{ High } & \multirow{2}{*}{$\begin{array}{l}\text { Total } \\
\mathbf{N}\end{array}$} & $\mathbf{X}^{2}$ & $\mathbf{P}$ \\
\hline & $\mathbf{N}$ & $\%$ & $\mathbf{N}$ & $\%$ & $\mathbf{N}$ & $\%$ & & \multirow{4}{*}{1.389} & \multirow{4}{*}{0.908} \\
\hline Mild & 9 & 24.3 & 20 & $\overline{54.1}$ & $\overline{8}$ & 21.6 & 37 & & \\
\hline Moderate & 7 & 24.1 & 17 & 58.6 & 5 & 17.2 & 29 & & \\
\hline Severe & 0 & 0 & 3 & 75 & 1 & 25 & 4 & & \\
\hline Total No. & \multicolumn{2}{|c|}{16} & \multicolumn{2}{|c|}{40} & \multicolumn{2}{|c|}{14} & 70 & & \\
\hline
\end{tabular}

Table (4): Relationship between patients' diagnosis and their levels of hospitalization related stress. $(n=70)$.

\begin{tabular}{|c|c|c|c|c|c|c|c|c|c|}
\hline \multirow{3}{*}{ Patients' diagnosis } & \multirow{3}{*}{$\begin{array}{c}\text { Total } \\
\text { no }\end{array}$} & \multicolumn{6}{|c|}{ Hospitalization related stress levels } & \multirow{3}{*}{$\mathbf{X}^{2}$} & \multirow{3}{*}{$\mathbf{P}$} \\
\hline & & \multicolumn{2}{|c|}{ Mild } & \multicolumn{2}{|c|}{ Moderate } & \multicolumn{2}{|c|}{ severe } & & \\
\hline & & $\mathbf{N}$ & $\%$ & $\mathbf{N}$ & $\%$ & $\mathbf{N}$ & $\%$ & & \\
\hline Schizophrenic disorder & 33 & 19 & 57.6 & 13 & 39.4 & 1 & 3 & \multirow{5}{*}{12.266} & \multirow{5}{*}{$\begin{array}{c}\mathbf{0 . 0 8 1} \\
(\mathrm{n} . \mathrm{s})\end{array}$} \\
\hline Mood disorder (Mania) & 10 & 2 & 20 & 5 & 50 & 3 & 30 & & \\
\hline Mood disorder(Depression) & 7 & 4 & 57.1 & 3 & 42.9 & 0 & 0 & & \\
\hline Schizoaffective disorder & 7 & 6 & 85.7 & 1 & 14.3 & 0 & 0 & & \\
\hline Other disorders & 13 & 6 & 46.2 & 7 & 53.8 & 0 & 0 & & \\
\hline
\end{tabular}

Table (5): Relationship between patients' diagnosis and their levels of perceived social support. ( $n=70$ ).

\begin{tabular}{|c|c|c|c|c|c|c|c|c|c|}
\hline \multirow{3}{*}{ Patients' diagnosis } & \multirow{3}{*}{$\begin{array}{r}\text { Total } \\
\text { No }\end{array}$} & \multicolumn{6}{|c|}{ Perceived social support levels } & \multirow{3}{*}{$\mathbf{X}^{2}$} & \multirow{3}{*}{$\mathbf{P}$} \\
\hline & & \multicolumn{2}{|c|}{ low } & \multicolumn{2}{|c|}{ Moderate } & \multicolumn{2}{|c|}{ High } & & \\
\hline & & $\mathbf{N}$ & $\%$ & $\mathbf{N}$ & $\%$ & $\mathbf{N}$ & $\%$ & & \\
\hline Schizophrenic disorder & 33 & 7 & 21.2 & 19 & 57.6 & 7 & 21.2 & \multirow{5}{*}{8.066} & \multirow{5}{*}{0.403} \\
\hline Mood disorder (Mania) & 10 & 2 & 20 & 6 & 60 & 2 & 20 & & \\
\hline Mood disorder(Depression) & 7 & 0 & 0 & 7 & 100 & 0 & 0 & & \\
\hline Schizoaffective disorder & 7 & 3 & 42.9 & 2 & 28.6 & 2 & 28.6 & & \\
\hline Other disorders & 13 & 4 & 30.8 & 6 & 46.2 & 3 & 23.1 & & \\
\hline
\end{tabular}

Table (1) reveals the distribution of psychiatric patients according to their hospital stress, it was found that, $79 \%$ and $71 \%$ of patients reported they had stress because of being hospitalized far away from home and being in the hospital during holidays. Also, $64 \%$ and $57 \%$ of patients reported that they had stress because of having to stay in the same bed or room and having sudden hospitalization respectively. Moreover, 56\% of patients had hospital stress related to thinking they might have pain from procedures.

Table (2) shows the distribution of psychiatric patients according to their perceived social support scale. This table illustrates that $31.3 \%$ and $30 \%$ of patients strongly agreed on getting emotional help and support from their families and counting on their friends. Also, $31.4 \%$ of them mildly agreed that their friends help them. On the other hand, $22.9 \%$ and $25.7 \%$ of patients reported that they neutrally agreed that a special person is a real source of comfort, they can talk with their families and their families help them making decisions.
However, $25.7 \%$ and $28.6 \%$ of them mildly disagreed that a special person is around when they are in need, a special person with whom they can share their joys and sorrows, a special person is a real source of comfort, a special person cares about their feelings and their families help them making decisions respectively. In addition, $28.6 \%$ and $30 \%$ of them strongly disagreed that a special person is around when they are in need, a special person with whom they can share their joys and sorrows and a special person is a real source of comfort.

Figure (1): shows that, $52.9 \%$ of psychiatric patients had low level of hospitalization related stress and $41.9 \%$ of them had moderate level of hospitalization related stress. Concerning to social support, it was found that, $22.9 \%$ of patients had low level of social support and $57.1 \%$ had moderate level of social support.

Table (3); shows that, there is no statistically significant association between levels of hospitalization stress and levels of social support. 
Table (4): illustrates relationship between diagnosis and levels of hospitalization related stress among psychiatric patients. It was found that, $30 \%$ of manic patients suffered from severe stress, while, 50\%, $42.9 \%$ and $53.8 \%$ of manic, depressed and other diagnostic patients respectively suffered from moderate hospital stress. There is no statistically relation between diagnosis and hospitalization stress levels with $\mathrm{P}=0.081$.

Table (5): shows the relationship between patients' diagnosis and there levels of social support. It was noticed that, $42.9 \%$ of schizoaffective patients perceived low level of social support, while, $57.6 \%$ of schizophrenic, $60 \%$ of manic and $100 \%$ of depressed patients perceived moderate level of social support. There is no significant relation between diagnosis and perceived social support levels with $\mathrm{P}=$ 0.403 .

\section{Discussion}

This study indicated that the majority of patients reported stress of being hospitalized far away from home and being in the hospital during holidays. It can be speculated that being hospitalized isolates patients from daily life activities and makes them unable to carry out marital and family roles.

This finding is consistent with the results of (Kim et al., 1991 and Latha \& Shankar, 2011) who found that most of both sexes especially the males reported stress of being hospitalized far away from home as it was inconvenient to stay away from home as most of males were either head of the family and main bread winner.

In contrast to the current study, (Koenig et al., 1995 Kimhy et al., 2004; Akpinar \& Buldukoglu, 2009 and Magdalena et al., 2012) reported that, all patients, without separating them by demographic or illness related characteristics who participated in the research identified having a psychiatric illness as causing the greatest stress. Based on this it was interesting that the greatest difficulty experienced by the patients was not related to their hospitalization but related to their illness.

The current study result revealed that, about one third of patients reported that they were strongly agreed on getting emotional help and support from their families and counting on their friends. Also, about one third of them were mildly agreed that their friends help them. This might be related to the fact that, usually the family members are the most important primary group that persons try to confide with them in the period of crisis or any stressful events. However, this again is dependent on their closeness with their kith and kin (Sachdeva \& Vidhya, 2000).
The current study result indicated the importance of family and revealed the need for creating support networks for the families and friends of mentally ill people and also for creating a wider social impact, aimed at a change of social attitudes, towards more approval and openness for mentally ill patients living in communities. In the same line with (Sawant \& Jethwani, 2010 \& Jodar, 1997) reported that social network of those with psychotic illness is around four to five; almost all of them would be family members. These results are also supported by (Clinton et al., 1998 \& Goldberg et al., 2003) where their studied patients mentioned that, their closest relatives and friends were the most frequently used support, which satisfy the need for emotional support to a considerably higher degree. While, (Harvey, 1996, Bengttsson et al., 2001; Nystrom \& Lutzen, 2002 \& Bronowski \& Załuska, 2008) reported that the scope of support wasn't the family.

The current study showed that, more than one third of the psychiatric patients had moderate level of hospital stress. This could be attributed to, psychiatric hospitalization to many patients considered a protection; they feel safe in the hospital and seem to adapt to hospitalization as if they were in their homes because of prolonged stay and also could be related to the good treatment of health team to them. Concerning to social support, nearly one quadrant of the psychiatric patients had low level of social support. While, most of them had moderate social support level. This could be related to; some patients live near to the hospital which encourages their families to visit them, while the others live far away from their homes which interfere with their families visits.

This result is in agreement with (Martin et al., 2001, Fernández et al., 2001, McCathie et al., 2002 \& Magdalena et al., 2012) who reported that, hospitalized chronic patients perceived hospitalization as a little stressing event and they had low levels of social support, the same authors added that, they suffered from the same effects of routine and protocols.

The current study revealed that, there was no statistically significant relation between hospital stress and social support. This result could be due to, hospital stress rating scale measured stressors that patients faced inside the psychiatric hospital not in their homes, which was unnecessary depend on the perceived support scale which measured the support which patients perceived from their family, friends and significant others not from professional health team, so it was logic that, there was no relationship between the hospital stress and the perceived support. Also, changes in social relationships were a natural part of psychiatric illnesses and not just related to 
being hospitalized. Moreover, most of them had a psychiatric illness for more than one year and they had been hospitalized for 4 times and/or more that let them more adaptable with the hospitalization.

Likewise, Misra et al., (2003) found that, contact with one's own culture such as friends and family weren't significantly correlated, but particularly helpful in reducing stressors and their consequent reactions.

However, (Lackner et al., 2010 \& Magdalena et al., 2012) reported that, perceived stress demonstrated an inverse relationship with social support indicating that patients who received inadequate support reported higher stress levels. In this respect, Amber (2007) \& Dzulkifli \& Adawiah (2010) found a significant negative correlation between social support and stress.

Also, the current findings contradicted with the fact that, social relationships and social support are potent variables that can reduce feelings of stress and defend health against the impact of stress, thus contributing to increases in both the quality and length of life (Jang et al., 2002 \& Leung, 2007).

The current study revealed that, high stress levels present in patients with mood disorders, as nearly one third of manic patients suffered from severe stress, while, half and nearly half of manic and depressed patients suffered from moderate hospital stress. This may be related to the nature of the disease as, manic patients are easily stimulated and they are using ineffective coping strategies, while, depressed patients have difficulties to cope with stress because they experience feeling of hopelessness. In this respect, Raingruber (2002) reported that, patients with the diagnosis of depression are blamed and ostracized more by society and this situation may make their hospitalization more difficulty and stressful.

This is also in agreement with the findings of (Dyson \& Renk, 2006) who found that, the high levels of stress were related to high levels of depressive symptomatology. Also, Seiffge \& Klessinger (2000) and Faleel et al. (2012) found that individuals who are having difficulties in alleviating or coping with stress are more likely to experience the feelings of depression which include hopelessness and sadness.

The current study revealed no statistically significant relation between hospital stress levels and diagnosis. In contrast, (Akpinar \& Buldukoglu, 2009 \& Magdalena et al., 2012) found that there was significant relation between hospital stress and diagnosis.

The current study revealed that, all depressed patients had moderate level of social support. It is believed that, individuals who have more restricted networks are most likely to exhibit signs of depression (Fiori et al., 2006), and nearly more than half of schizophrenic patients had moderate level of social support. This is partially supported by (Clinton et al., 1998) who reported that, $60 \%$ of schizophrenic patients reported the need for increased emotional support, especially in the areas of advice and trustrelated matters.

There was no significant relation between diagnosis and social support levels. The current result is supported by (Yang et al., 2009) who found no significant relation between social support levels and diagnosis and interpreted the findings by that, these patients usually found a lower level of support from close relationships. Moreover, this may be a protective mechanism learnt over time so that a person with depression and schizophrenia avoids engaging in too many stressful relationships.

Gigantesco et al., (2010) proved that, approximately one third of psychiatric inpatients had no close relationships or social support.

\section{Conclusions}

Based on the results of the present study it could be concluded that, being hospitalized far away from home and being in the hospital during holidays were the major reasons for hospital related stress experienced by psychiatric patients. Concerning to social support, nearly one quadrant of the psychiatric patients had low level of social support, while, most of them had moderate social support level. This could be related to; some patients live near to the hospital which encourages their families to visit them, while the others live far away from their homes which interfere with their families visits. There was no statistically significant relation between hospital stress and social support. The results also showed that, high stress levels present in patients with mood disorders. Meanwhile, moderate level of social support presents in all depressed and more than half of schizophrenic patients, while there is no statistically significant relation between diagnosis and hospital stress levels and social support as well.

\section{Recommendations based on results}

1. Psycho educational programs are essential to educate psychiatric patients how to deal with hospitalization related stress and increase social support for them.

2. Health education for patients, families and friends about the importance of social support.

3. Further studies are needed to assist in generalization of the findings 


\section{References}

1. Akpinar H., \& Buldukoglu K., (2009): Hospital Stressors Experienced By Elderly Psychiatric Inpatients. New/Yeni Symposium Journal. Ocak 2009| Cilt 47 | Say, available at: www.yenisymposium.net.

2. Amber L., (2007): the role of social support, self efficacy and optimism in physical health impact on depressive and anxious symptoms among older adult. Proquest dissertation and theses, in Partial Fulfillment of the Requirements for the Degree Doctor of the faculty of the department of psychology university of Houston. Chapter 7: 47.

3. Bengttsson G., Tops A., \& Hansson L., (2001): Quantitative and Qualitative aspects of the social network in schizophrenic patients living in the community, relationship to socio demographic characteristics and clinical factors and subjective quality of life. Social Psychiatry and psychiatric Epidemiology, 47(3): 67-77.

4. Bronowski P., \& Zaluska M., (2008): Social support of chronically mentally ill patients, Archives of Psychiatry and Psychotherapy, 2: 13-19.

5. Calvete H., \& Smith K., (2006): Perceived Social Support, Coping, and Symptoms of Distress in American and Spanish Students. Anxiety, Stress, and Coping, 19(1): 47 - 65.

6. Clinton M., Lunney P., Edwards H., Weir R., \& Barr J., (1998): Perceived social support and community adaptation in schizophrenia. Journal of Advanced Nursing, 27: 955-965.

7. Dan-Set G., Telford, \& Shropshire., (2007): The psychological care of medical patients A practical guide, Report of a joint working party of the Royal College of Physicians and the Royal College of Psychiatrists. Psychological responses to illness: 18:22.

8. Di Matteo, M., (2004): Social Support and Patient adherence to Medical Treatment: A metaanalysis. Health Psychology, 23: 207-218.

9. Dirkzwager A., Bramsen I., Henk M., \& Ploeg V., (2003): Social support, coping, life events, and posttraumatic stress symptoms among former peacekeepers: a perspective study in india; 34: 1545-1559

10. Dollete S., Phillips K., \& Matthews P., (2004): Understanding girls' circle as an intervention on perceived social support, body image, selfefficacy, locus of control and self-esteem. The Journal of Psychology, 90 (2): 204-215.

11. Dyson R., \& Renk K., (2006): Freshmen Adaptation to University Life: Depressive symptoms, Stress and Coping. Journal of Clinical Psychology, 62: 1231 - 1244.

12. Dzulkifli Y., \& Adawiah M., (2010): The Relationship between Social Support and Psychological Problems among Students. nternational Journal of Business and Social Science Vol. 1 No. 3: 110 : 115. Available at: www.ijbssnet.com.

13. Eskin M., (2003): Self-reported assertiveness in Swedish and Turkish adolescents: A crosscultural comparison. Scandinavian Journal of Psychology, 44: 7-12.

14. Faleel F., Tam C., Lee H., Har W., \& Chu F., (2012): Stress, Perceived Social Support, Coping Capability and Depression: A Study of Local and Foreign Students in the Malaysian Context. World Academy of Science, Engineering and Technology. No 61:75 - 80.

15. Fernández A., Bujalance M., Leiva F., Martos F., García A., \& Sánchez F., (2001): Salud autopercibida, apoyo social y familiar de los pacientes con enfermedad pulmonar obstructiva crónica. Aten Pri, 28: 579- 589.

16. Fiori L., Katherine., Antonucci C., Toni., \& Cortina K., (2006): Social Network Typologies and Mental Health Among Older Adults. The Journals of Gerontology Series B: Psychological Sciences and Social Sciences, 61B, no. 1: 25-32.

17. Gigantesco A., De Girolamo G., Santone R., Miglio \& Picardi A., (2010): Long-stay and short-stay. inpatient facilities: risk factors and barriers to discharge. BMC Public Health. Retrieved on: 15/5/2010. Available at: http://creativecommons.

18. Goldberg R., Rollins A., \& Lehman A., (2003): Social network correlates among people with psychiatric disabilities. Psychiatric Rehabilitation Journal, 26: 393-404.

19. Harvey C., (1996): The Camden schizophrenia survey. The psychiatric behavioral and social characteristics of the severely mentally ill in an inner London health district. British Journal of Psychiatry, 168: 410-417.

20. Jang Y., Haley W., Small B., \& Mortimer J., (2002): The role of mastery of and social resources in the association between disability \& depression in later life. The gerontologist, 42(6): 607-813.

21. Jodar L., (1997): Caring for Caregivers: Perceptions of Social Support. Journal of Psychosocial Nursing, 35: 17-24.

22. Kim W., Hahn S., Kish J., Rosenberg L., \& Harris J., (1991): Separation reaction of psychiatrically hospitalized children: A pilot study. Child Psychiatry and Human Development, 22'53-67. 
23. Kimhy D., Harkavy J., \& Nelson E., (2004): Identifying life stressors of patients with schizophrenia at hospital discharge. Psychiatry Service; 55: 1444-1445.

24. Koenig H., George L., Stangl D., \& Tweed D., (1995): Hospital stressors experienced by elderly medical inpatients: Developing a hospital stress index. Int J Psychiatry Med; 25: 103-122.

25. Krakowski M., \& Czobor P., (1997): Violence in psychiatric patients. The role of psychosis, frontal lobe impairment and ward turmoil. Compr Psychiatry; 38:230-236.

26. Lackner J., Brasel A., Quigley B., Lkeefer S., Krasner, powell c., Katz L., \& Sitrin M., (2010): The ties that bind: perceived social support, stress, and IBS in severely affected patients. Neurogastroenterology and Motility Vol, 22, N0, 8,: 893 ;900.

27. Latha K., \& Shankar B., (2011): Hospital Related Stress Among Patients Admitted to a Psychiatric In-patient Unit in India. Online J Health Allied Scs.; 10(1):5 available at: http://www.ojhas.org/issue37/2011-1-5.htm.

28. Leung L., (2007): Stressful Life Events, Motives for Internet Use, \& Social Support Among Digital Kids. cyberpsychology \& behavior Volume 10, Number 2: 204-213.

29. Magdalena M., Juan J., Montaño M., Maria J., Victoria F., Feliu R., Belen M., \& Catalina A., (2012): Stress associated with hospitalization in patients with COPD: the role of social support and health related quality of life. Multidisciplinary Respiratory Medicine available at: http://www.mrmjournal.com/content/7/1/51.

30. Martin M., Grünendahl M., \& Martin P., (2001): Age differences in stress, social resources, and well-being in middle and older age. J Gerontol B Psychol Sci Soc Sci, 56:214222.

31. McCathie F., Spence S., \& Tate R., (2002): Adjustment to chronic obstructive pulmonary disease: the importance of psychological factors. Eur Respir J, 19:47-53.

32. Misra R., Crist M., \& Burant C., (2003): Relationships among Life Stress, Social Support, Academic Stressors, and Reactions to Stressors of International Students in the United States. International Journal of Stress Management, 10: 137-157.

33. Muller B., Nordt C., Lauber \& Rossler W., (2007): Changes in Social Network Diversity and perceived Social Support after psychiatric. Hospitalization: Results from a longitudinal Study. International J. Soc. Psychiatry, 53: 564575 .
34. Nijman H., (2002): A model of aggression in psychiatric hospitals. Acta Psychiatr Scand: 106 (Suppl. 412): 142-143. ISSN 0065-1591.

35. Nystrom M., \& Lutzen K., (2002): Psychiatric care service, an exploration of the professional world encountered by persons with long - term mental illness. Scand J Caring Sci, 16: 171178.

36. Raingruber B., (2002): Client and provider perspectives regarding the stigma of and non stigmatizing interventions for depression. Archives Psychiatric Nurs; 16: 201-207.

37. Sachdeva D., Vidhya A., (2000): Family in India: An Introduction to Sociology 2nd (ed), Kitab Mahal, Allahabad: 110-112.

38. Sawant N., \& Jethwani K., (2010): Understanding family functioning and Social Support in unremitting schizophrenia: A study in India. Indian J. Psychiatry, 52: 145-149.

39. Seiffge K., \& Klessinger N., (2000): Long-term effects of avoidant coping on adolescents' depressive symptoms. Journal of Youth and Adolescence, 29: 617-628.

40. Sorkin D., Rook K., \& Lu J., (2002): Loneliness, lack of emotional support, lack of companionship, and the likelihood of having a heart condition in an elderly sample. Annals of Behavioral Medicine, 24:290-298.

41. Tao S., Dong Q., Pratt M., Hunsberger B., \& Pancer S., (2000): Social support: Relations to coping and adjustment during the transition to university in the People's Republic of China. Journal of Adolescent Research, 5(1): 123-144.

42. Volicer B., \& Bohannon M., (1975): A hospital stress rating scale. Nurs Res, 24:352-9.

43. Yang Y., Hawkley L., \& Christakis N., (2009): Social Support, Networks, and Happiness. Population Reference Bureau. Today's Research on Aging .No. 17: 330-338.

44. Zimet G., Powell S., Farley G., Werkman S., \& Berkoff K., (1990): Psychometric characteristics of the Multidimensional Scale of Perceived Social Support. Journal of Personality Assessment, 55: 610-17. 